\title{
Фотопроводимость и поглощение инфракрасного излучения в квантовых ямах $p$-GaAs/AIGaAs
}

\author{
(С) М.Я. Винниченко ${ }^{1}$, И.С. Махов ${ }^{1}$, Н.Ю. Харин ${ }^{1}$, С.В. Графр ${ }^{1}$, В.Ю. Паневин ${ }^{1}$, \\ И.В. Седова ${ }^{2}$, С.В. Сорокин ${ }^{2}$, Д.А. Фирсов ${ }^{1}$ \\ ${ }^{1}$ Санкт-Петербургский политехнический университет Петра Великого, \\ 195251 Санкт-Петербург, Россия \\ ${ }^{2}$ Физико-технический институт им. А.Ф. Иоффе Российской академии наук, \\ 194021 Санкт-Петербург, Россия \\ E-mail: mvin@spbstu.ru
}

Поступила в Редакцию 9 апреля 2021 г.

В окончательной редакции 19 апреля 2021 г.

Принята к публикации 19 апреля 2021 г.

\begin{abstract}
Выполнены исследования спектров низкотемпературной примесной фотопроводимости, а также примесного поглощения в наноструктуре с множественными квантовыми ямами $\mathrm{GaAs} / \mathrm{AlGaAs}$, легированными акцепторами, в средней и дальней инфракрасных областях спектра. Полученные экспериментально спектры поглощения и фотопроводимости хорошо коррелируют друг с другом. В соответствии с расчетом энергетического спектра дырочных и акцепторных состояний в квантовых ямах идентифицированы вклады в поглощение и фототок от переходов дырок из основного акцепторного состояния в делокализованные состояния валентных подзон и на возбужденные состояния примеси, а также от процессов фотоионизации акцепторов в состояния над квантовой ямой.
\end{abstract}

Ключевые слова: квантовые ямы, примеси, акцепторные уровни, фотопроводимость, поглощение.

DOI: $10.21883 /$ FTP.2021.08.51127.03

\section{1. Введение}

Исследование примесных состояний в полупроводниках вызывает интерес с точки зрения возможности создания источников и детекторов излучения среднего и дальнего инфракрасного (ИК) диапазонов на их основе. Приборы, работающие в данных диапазонах спектра, могут найти применение во многих областях науки и техники: в медицине, системах безопасности, диагностике различных материалов и т.д. [1-4]. К настоящему времени уже сообщалось о наблюдении дальнего ИК (терагерцового) излучения при внутрицентровых примесных оптических переходах. Такое излучение было обнаружено и исследовано в объемных $n-\mathrm{Si}$ [5] и $p$-Si [6] при оптической накачке излучением $\mathrm{CO}_{2}$-лазера и лазера на свободных электронах, а также в $n$-GaAs и $p$-Ge [7] в условиях межзонного оптического возбуждения. Кроме того, эмиссия терагерцового излучения, связанного с примесными переходами неравновесных носителей заряда, также наблюдалась в условиях пробоя мелких примесных центров электрическим полем в объемных полупроводниках [8].

Использование квантовых ям (КЯ) расширяет возможности исследования эмиссии излучения, поскольку энергетический спектр примесного центра в квантовой яме зависит как от ширины ямы, так и от местоположения самого примесного центра [9], что может расширить рабочий спектральный диапазон устройств на основе легированных КЯ по сравнению с легированными объемными полупроводниками. Исследованию оптических свойств наноструктур с КЯ, легированными донорными примесными центрами, посвящено значительное число работ. Например, в работах $[10,11]$ проводились теоретические и экспериментальные исследования энергетического спектра доноров в квантовых ямах $\mathrm{Si} / \mathrm{SiGe}$ и сверхрешетках $\mathrm{GaAs} / \mathrm{AlGaAs}$ соответственно. Люминесценция дальнего ИК-диапазона, связанная с донорными примесными переходами электронов, наблюдалась в условиях межзонного оптического возбуждения квантовых ям GaAs/AlGaAs [12]. Было исследовано влияние стимулированного ближнего инфракрасного излучения и компенсации примесей на интенсивность и спектры терагерцовой фотолюминесценции, связанной с донорными примесными переходами электронов в КЯ GaAs/AlGaAs [13,14].

Оптические свойства акцепторов в квантовых ямах изучены не так подробно. В этом случае сложная структура валентной зоны и спектра примесных состояний, нетривиальная поляризационная зависимость оптических эффектов затрудняют теоретические расчеты и интерпретацию экспериментальных результатов [15]. Однако у КЯ, легированных акцепторной примесью, имеются свои преимущества: (i) значительная энергия связи акцепторов позволяет продвинуться в коротковолновую область спектра за пределы полосы остаточных лучей, в которой слабее проявляется решеточное поглощение, (ii) согласно правилам отбора, в структурах с КЯ $p$-типа возможны межподзонные оптические переходы для нормального падения света, т. е. для излучения поперечно-электрической (ТЕ) поляризации, что перспективно для создания ИК-фотоприемников и модуляторов [16]. 
Данная работа посвящена исследованию поглощения и фотопроводимости в инфракрасной области спектра, связанных с акцепторными состояниями в КЯ GaAs/AlGaAs.

\section{2. Расчет энергетического спектра и волновых функций дырок и акцепторов в квантовых ямах}

Расчет энергетического спектра дырок и акцепторов в квантовых ямах $p$-типа был выполнен с учетом сложной структуры валентной зоны. В основе методики расчета лежит разложение волновой функции дырки в кулоновском потенциале акцепторной примеси в ряд по состояниям подзон валентной зоны в квантовой яме в отсутствие акцептора (детали расчета изложены в [17]). Для нахождения последних с учетом сложного строения валентной зоны производилось численное квантование гамильтониана Латтинжера в аксиальном приближении с учетом различия параметров материалов ямы и барьера. Для этого уравнение Шредингера записывалось в виде системы связанных дифференциальных уравнений, которая решалась численно методом конечных разностей для ряда дискретных значений волнового вектора дырки в плоскости ямы с целью нахождения дисперсии подзон размерного квантования и плавных огибающих волновых функций дырок в прямоугольном одномерном потенциале квантовой ямы.

Разложение волновых функций дырок в кулоновском поле акцепторной примеси приводит к необходимости расчета матричных элементов кулоновского потенциала, построенных на состояниях квантованных подзон валентной зоны в отсутствие акцептора. Были получены выражения для данных матричных элементов, которые позволили на дискретной сетке в пространстве волновых векторов построить конечномерную матрицу, численная диагонализация (или поиск собственных чисел и собственных векторов) которой позволяет прямо рассчитать зависимости коэффициентов разложения от двумерного волнового вектора и энергии для состояний дырок в поле кулоновского потенциала акцептора в квантовой яме. При этом естественным образом получается полный набор состояний: локализованные состояния под нижней подзоной размерного квантования, причем средний волновой вектор в них равен нулю; состояния сплошного спектра в кулоновском потенциале выше края подзоны размерного квантования (коэффициенты разложения для которых представляют собой узкий пик в k-пространстве, соответствующий состоянию с определенным k в зоне в отсутствие акцептора); резонансные состояния, представляющие собой „суперпозицию“ первых двух (коэффициенты разложения содержат как „локализованную“, так и распространяющуюся части).

Рассчитанный энергетический спектр дырочных и акцепторных состояний для КЯ $\mathrm{GaAs} / \mathrm{Al}_{0.4} \mathrm{Ga}_{0.6} \mathrm{As}$ шириной 3 нм приведен на рис. 1. При расчетах полагалось, что примесь расположена в центре КЯ.

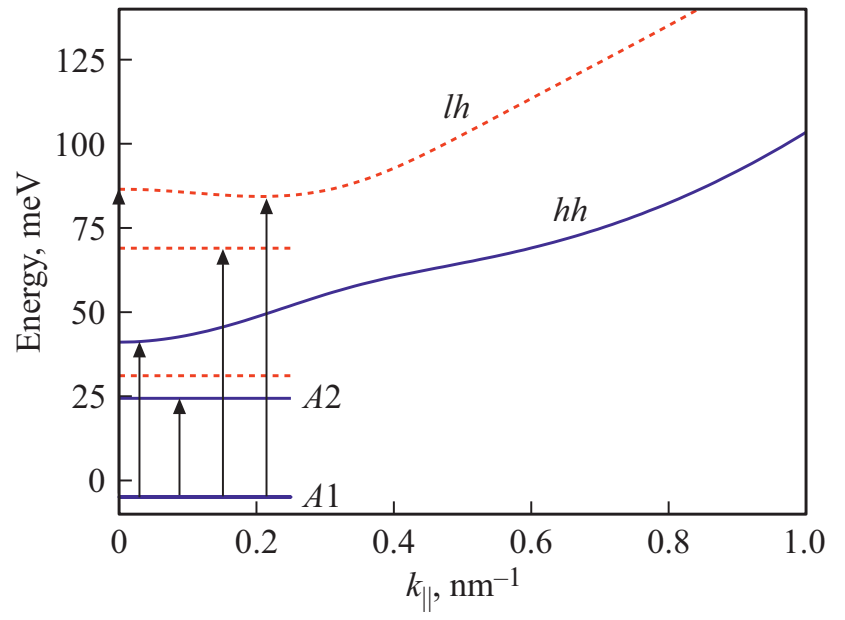

Рис. 1. Рассчитанный закон дисперсии первых дырочных подзон и энергетическое положение уровней акцепторов (показано схематически, без учета степени локализации примесных состояний в k-пространстве). Стрелками отмечены основные переходы, наблюдаемые в экспериментальных спектрах фотопроводимости и поглощения.

\section{3. Образцы и методика эксперимента}

Структура, содержащая 200 квантовых ям, сформированных слоями GaAs шириной $3 \mathrm{Hм} \mathrm{и} \mathrm{Al}_{0.4} \mathrm{Ga}_{0.6} \mathrm{As}$ толщиной 7 нм, была выращена методом молекулярнопучковой эпитаксии на полуизолирующей подложке $\mathrm{GaAs}$, ориентированной в плоскости (001). Слои толщиной 0.7 нм в центре квантовых ям легировались акцепторами Ве с поверхностной концентрацией $1 \cdot 10^{11} \mathrm{~cm}^{-2}$. Из пластины с выращенными эпитаксиальными слоями были изготовлены образцы для оптических и электрооптических измерений. Для измерения примесного поглощения были изготовлены образцы в многопроходной геометрии. Для этого две противоположные грани образца были сточены под углом $45^{\circ}$. Такая геометрия позволяет исследовать поглощение света с поляризацией как вдоль поверхности образца, так и вдоль оси роста. Размеры образца подбирались таким образом, чтобы излучение проходило через слои с КЯ 12 раз. При этом суммарная длина оптического пути в слоях квантовых ям составила 11.5 мкм. Для того чтобы учесть вклад подложки в спектр поглощения, был также подготовлен образец, в котором слои с КЯ были механически удалены.

Для проведения электрооптических исследований на поверхности образцов формировались латеральные контакты путем нанесения тонких полосок индия и последующего отжига в азотной атмосфере в следующем цикле: плавный нагрев образца до $450^{\circ} \mathrm{C}$ в течение 5 мин, затем поддержание температуры в течение 5 мин, а после этого остывание до комнатной температуры в течение 5 мин. Расстояние между контактами составляло 5.1 мм, длина контактов 5.8 мм. 
Характеризация выращенных структур была проведена с помощью анализа спектров ближней ИК-фотолюминесценции, полученных на автоматизированной установке на базе решеточного монохроматора Horiba FHR-640, оснащенного голографической дифракционной решеткой, содержащей 1200 штр/мм, а также охлаждаемой жидким азотом кремниевой ПЗС-матрицей, используемой в качестве детектора излучения. Для оптической накачки образца использовалось излучение твердотельного лазера $\mathrm{Nd}$ :YAG с удвоением частоты в кристалле иодата лития, работающего в непрерывном режиме генерации. Длина волны излучения накачки составляла 532 нм. Образец помещался в заливной азотный вакуумный криостат с окнами из плавленого кварца.

Спектры межподзонного поглощения изучались с помощью вакуумного фурье-спектрометра Bruker Vertex $80 \mathrm{v}$ для двух поляризаций света (ТЕ, ТМ). В качестве источника ИК-излучения был использован глобар. Образец помещался в криостат замкнутого цикла Janis РТСМ-4-7, позволяющий проводить измерения в диапазоне температур от 4 до $300 \mathrm{~K}$. Окна криостата и светоделитель спектрометра были выполнены из $\mathrm{KBr}$. Прошедшее через образец излучение регистрировалось пироэлектрическим фотодетектором DLaTGS. Спектрометр работал в режиме непрерывного сканирования (rapid scan) со спектральным разрешением $\sim 1$ мэВ.

Для получения спектров латеральной фотопроводимости также использовался фурье-спектрометр Bruker Vertex 80v, работающий в режиме непрерывного сканирования. В качестве источника широкополосного излучения использовался глобар. В спектрометре использовались светоделители из $\mathrm{CaF}_{2}, \mathrm{KBr}$ и Mylar для исследований в ближнем, среднем и дальнем ИК-диапазонах соответственно. При проведении измерений в среднем и ближнем ИК-диапазонах спектра входные окна криостата были выполнены из $\mathrm{KBr}$, в дальнем ИКдиапазоне использовались окна из полиметилпентена (TPX). Для предотвращения нежелательной ионизации примесей внешним фоновым тепловым излучением образец в криостате был защищен холодным экраном, закрепленным на первой ступени охлаждения криостата $(T=60 \mathrm{~K})$. Излучение глобара направлялось на образец с помощью тонкого полированного световода из нержавеющей стали, направленного сквозь экран к окну криостата. Световод имел прижимной контакт с держателем образца. Измерения фотопроводимости проводились при напряжении смещения на образце $5 \mathrm{~B}$, измерение фототока в образце осуществлялось с помощью токового предусилителя SR-570.

\section{4. Результаты и их обсуждение}

\section{1. Предварительная характеризация образцов}

Для определения энергии связи акцепторов $E_{A}$ в КЯ была измерена температурная зависимость удельной электропроводности. При анализе полученной температурной зависимости проводимости мы предположили, что подвижность дырок слабо зависит от температуры, и использовали пропорциональность проводимости и концентрации свободных дырок. Температурная зависимость концентрации носителей заряда в квантовой яме была рассчитана с учетом одного типа нескомпенсированных акцепторов. Для этого использовалось известное выражение для концентрации носителей заряда $N_{h}$ в объемном полупроводнике [18]

$$
N_{h}=\sqrt{\beta N_{V} N_{A}} \exp \left(-\frac{E_{A}}{2 k T}\right)
$$

с заменой объемной эффективной плотности состояний на соответствующую двумерную

$$
N_{V}=\frac{m k T}{\pi \hbar^{2}}
$$

где $\beta$ - фактор вырождения основного акцепторного состояния, $N_{A}$ - поверхностная концентрация акцепторной примеси. Отметим также, что мы считали газ носителей заряда невырожденным, т.е. полагали, что концентрация свободных дырок значительно меньше, чем эффективная плотность состояний в подзоне тяжелых дырок, что выполняется для нашей структуры во всем исследуемом температурном диапазоне. С использованием такой аппроксимации было получено значение энергии ионизации акцепторной примеси в квантовых ямах $\sim 40$ мэВ. Полученное значение хорошо согласуется с величиной энергии связи акцепторов в квантовых ямах исследуемой наноструктуры, полученной нами из расчета энергетического спектра акцепторов в КЯ (44 мэВ, см. рис. 1), а также с данными других авторов $[19,20]$.

Для характеризации образцов также были измерены и проанализированы спектры ближней ИК-фотолюминесценции, полученные при различных температурах кристаллической решетки (см. рис. 2). Было получено хорошее соответствие расчетных значений энергий межзонных оптических переходов носителей заряда в КЯ с положением пиков излучения в спектрах ближней инфракрасной фотолюминесценции наноструктуры. При комнатной температуре в спектрах ближней ИК-фотолюминесценции были обнаружены полосы излучения, связанные с излучательной электронно-дырочной рекомбинацией между первой электронной подзоной $(e 1)$ и первыми подзонами тяжелых $(h h)$ и легких $(l h)$ дырок валентной зоны. При этом слабоинтенсивное плечо на длинноволновом краю этого спектра фотолюминесценции может быть связано с вкладом излучательных переходов носителей заряда между первой электронной подзоной и акцепторными состояниями в КЯ. Разложение спектра фотолюминесценции, измеренного при комнатной температуре, на два кон- 


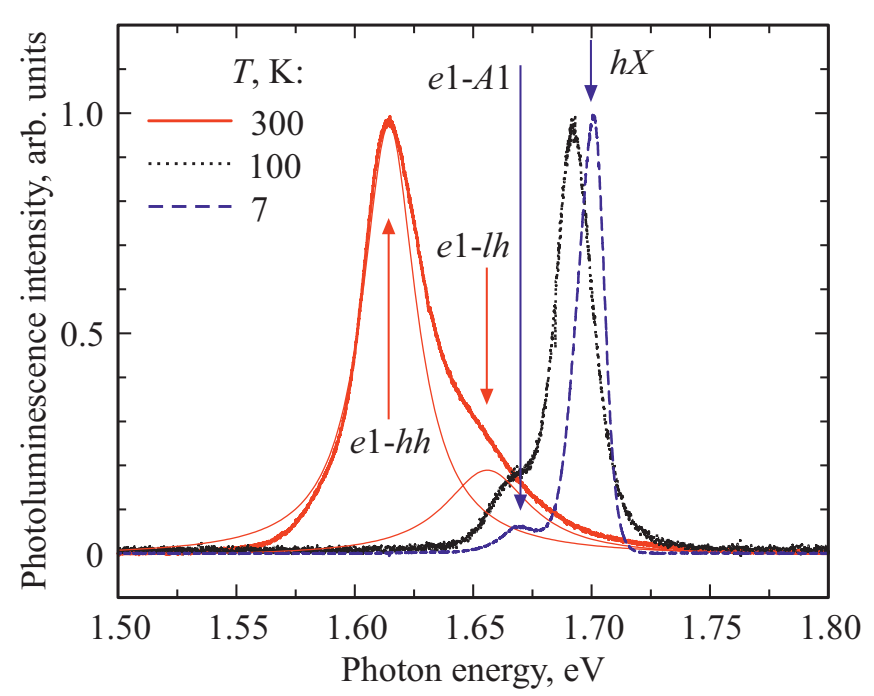

Рис. 2. Нормированные спектры фотолюминесценции в ближней ИК-области при разных температурах. Спектр при комнатной температуре разложен на два контура Лоренца. (Цветной вариант рисунка представлен в электронной версии статьи).

тура Лоренца показано более тонкими кривыми на рис. 2. Как можно видеть, расстояние между пиками люминесценции, связанными с переходами $e 1-h h 1$ и $e 1-l h 1$, соответствует расчетному значению энергетического зазора между подзонами тяжелых и легких дырок вблизи $k_{\|}=0$ (см. рис. 1). В спектрах фотолюминесценции, полученных при криогенных температурах, уже явно проявляется пик, связанный с переходами носителей заряда между первой электронной подзоной и основным акцепторным состоянием (стрелка $e 1-A 1$ на рис. 2), а также пик, связанный с рекомбинацией тяжелых свободных экситонов (стрелка $h X$ на рис. 2). Отсутствие пика люминесценции, связанного с переходами электронов в подзону легких дырок, при низких температурах решетки объясняется уменьшением заселенности верхних подзон фотовозбужденными дырками из-за уменьшения теплового размытия их функции распределения. Наблюдаемое с уменьшением температуры кристаллической решетки смещение полос фотолюминесценции в коротковолновую область связано с увеличением ширины запрещенной зоны. При температуре $7 \mathrm{~K}$ энергетический зазор между пиками $e 1-A 1$ и $h X$ составляет величину 29 мэВ. С учетом того что энергия свободного тяжелого экситона в КЯ $\mathrm{GaAs} / \mathrm{Al}_{0.4} \mathrm{Ga}_{0.6} \mathrm{As}$ шириной $3 \mathrm{Hм}$ составляет величину $\sim 11$ мэВ [21], можно сделать вывод, что энергия ионизации акцепторов в КЯ наноструктуры близка к $E_{A}=40$ мэВ. Это значение хорошо согласуется как с нашим расчетом энергетического спектра акцепторных состояний в КЯ, так и со значением энергии связи акцепторов, полученным из анализа температурной зависимости электропроводности.

\section{2. Исследование спектров фотопроводимости в наноструктурах с квантовыми ямами}

В измеренных низкотемпературных спектрах ближней ИК-фотопроводимости (см. рис. 3) фототок в образце резко возрастает вблизи энергии кванта, соответствующей ширине запрещенной зоны GaAs. Это можно связать с вкладом в фототок от подложки GaAs, а также от буферного и покровных слоев GaAs. B то же время в спектре наблюдаются провалы фототока при энергиях фотонов, соответствующих расчетным значениям энергий оптических переходов, связанных с образованием тяжелых $(h X)$ и легких $(l X)$ свободных экситонов в КЯ. Провалы в спектре фотопроводимости, вызванные образованием свободных экситонов, объясняются тем, что экситоны не вносят вклад в фототок при низких температурах кристаллической решетки. Положительный вклад экситонов в фототок, вероятно, мог бы наблюдаться при более высоких температурах решетки, когда энергия теплового движения носителей заряда сравнима с энергией связи экситона, т. е. в ситуации, когда образованный под воздействием света экситон может дать вклад в фототок вследствие термической диссоциации на неравновесные электрон и дырку в подзонах зоны проводимости и валентной зоны. Спектральное положение провала в спектре фототока, связанного с формированием свободных тяжелых экситонов (отмечен стрелкой $h X$ на рис. 3), совпадает с положением пика излучения в спектре ближней инфракрасной фотолюминесценции наноструктуры, связанного с рекомбинацией свободных тяжелых экситонов в КЯ (см. рис. 2).

На рис. 4 и 5 приведены спектры фотопроводимости наноструктуры, полученные для ТЕ-поляризованного света в различных спектральных диапазонах при различных температурах. Положение пиков фототока

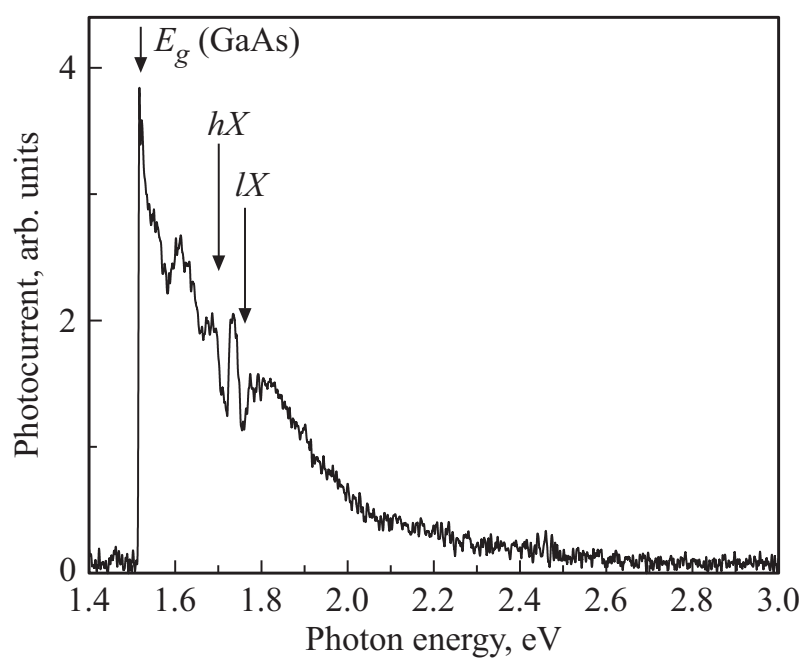

Рис. 3. Спектр фотопроводимости в ближней ИК-области спектра, измеренный при $T=7 \mathrm{~K}$. Стрелками показаны рассчитанные энергии оптических переходов. 


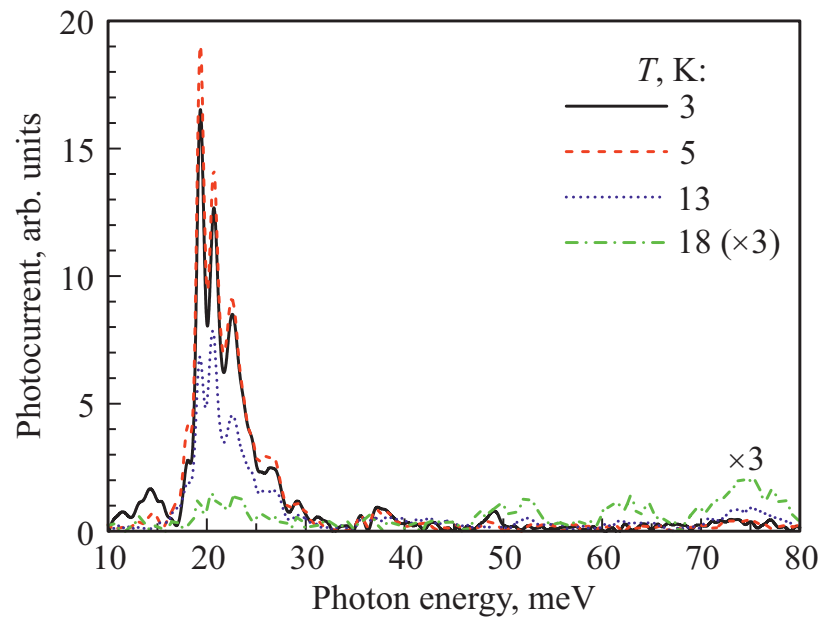

Рис. 4. Спектры фотопроводимости, измеренные в дальней ИК-области спектра при разных температурах. Значения фототока при $18 \mathrm{~K}$ увеличены в 3 раза во всем спектральном диапазоне. (Цветной вариант рисунка представлен в электронной версии статьи).

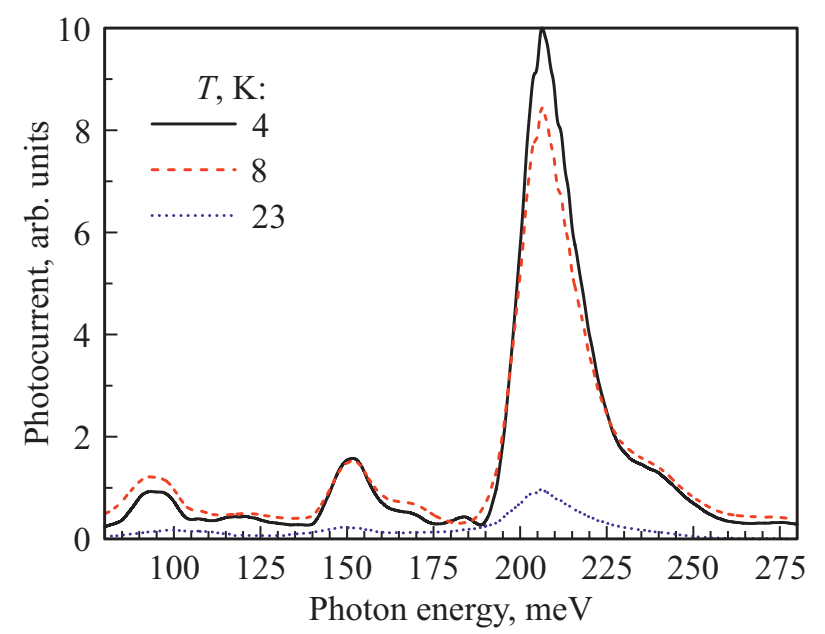

Рис. 5. Спектры фотопроводимости, измеренные в среднем ИК-диапазоне при разных температурах. (Цветной вариант рисунка представлен в электронной версии статьи).

хорошо согласуется с зонной диаграммой (основные переходы, проявляющиеся в спектрах фототока, отмечены стрелками на рис. 1). Широкую полосу фототока вблизи энергии кванта $\sim 20$ мэВ (см. рис. 4) мы связываем с оптическими переходами дырок из основного состояния акцепторной примеси $(A 1)$ на первое возбужденное состояние в КЯ (A2), откуда впоследствии они термически забрасываются в первую подзону валентной зоны и дают вклад в фототок. Наличие большого числа особенностей у этой полосы фототока может быть связано с дополнительным вкладом в фототок от примесных переходов дырок с участием состояний фоновых акцепторных примесей, находящихся в подложке и эпитаксиальных слоях структуры и возникающих в процессе роста GaAs методом Чохральского [22] или методом молекулярно- пучковой эпитаксии [23]. Пик вблизи энергии кванта 40 мэВ соответствует оптическим дырочным переходам из основного состояния примеси на дно первой подзоны дырок $h h$. Пики при энергиях кванта света $\sim 50,63$ и 75 мэВ связаны с внутрицентровыми переходами дырок из основного примесного состояния на возбужденные резонансные состояния примеси, относящиеся ко второй дырочной подзоне $l h$. Пик фототока при энергии кванта, близкой к 90 мэВ (см. рис. 5), связан с оптическими переходами дырок из основного состояния акцепторной примеси на состояния вблизи дна второй дырочной подзоны $l h$ вблизи $k_{\|}=0$. Наблюдаемый пик фототока вблизи энергии кванта 150 мэВ мы связываем с переходами дырок из основного примесного состояния на дно третьей дырочной подзоны (или второй подзоны тяжелых дырок, на рис. 1 она не показана). Так как в расчете мы использовали разложение волновой функции дырки по состояниям только первых двух подзон валентной зоны, то для получения значения энергии размерного кантования третьей дырочной подзоны мы использовали стандартное решение уравнения Шредингера в рамках параболической модели. Широкий пик вблизи энергии кванта $\sim 205$ мэВ связан с оптическими переходами дырок из основного акцепторного состояния в состояния континуума над КЯ. Природа небольшого плеча в фототоке при энергии кванта $\sim 240$ мэВ до конца не ясна. Она может быть связана с особенностями в приведенной плотности состояний в непрерывном спектре над КЯ или вкладом от глубоких примесных центров в слоях наноструктуры [24,25]. Положения всех пиков фототока, уширяющихся с повышением температуры, хорошо согласуются с теоретическим расчетом. Реперные образцы без КЯ не демонстрировали никаких особенностей в фототоке в данном спектральном диапазоне. Это подтверждает, что все особенности, наблюдаемые в спектрах фотопроводимости квантовых ям, связаны с примесными переходами.

\section{3. Исследование спектров поглощения света В наноструктурах с квантовыми ямами}

Поскольку спектральные особенности примесного поглощения в квантовых ямах, легированных акцепторами, зависят от поляризации излучения [17], эксперимент проводился в многопроходной геометрии образца. Для излучения ТЕ-поляризации вектор поляризации лежит в плоскости слоев с КЯ, для излучения ТМ-поляризации вектор поляризации содержит компоненту, параллельную оси роста структуры. Были измерены спектры интенсивности света, прошедшего через образец с КЯ и через реперный образец, в многопроходной геометрии для двух поляризаций света в широком диапазоне температур 4-300 K. Для получения спектров примесного поглощения при двух поляризациях света использовались закон Бугера-Ламберта-Бера и две методики. В первом методе для получения спектров поглощения ТМ-поляризованного света квантовыми ямами в 


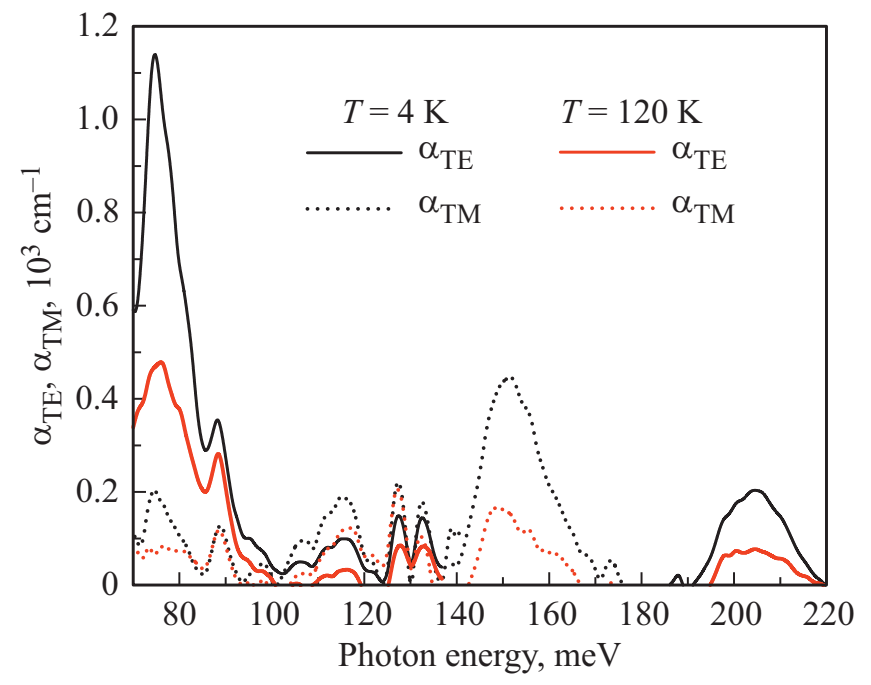

Рис. 6. Спектры поглощения для двух поляризаций света при разных температурах. (Цветной вариант рисунка представлен в электронной версии статьи).

качестве репера учитывались спектры интенсивности ТЕ-поляризованного света и спектры образцов без КЯ. Во втором методе для получения спектров поглощения ТМ-поляризованного излучения в качестве референса учитывались только спектры пропускания ТМ-волны в образцах без КЯ. Первый метод оказался более чувствительным и позволил обнаружить большее количество особенностей в широком диапазоне частот, однако он позволяет явным образом выделить пики поглощения только при тех интервалах энергии кванта, где основной вклад в поглощение дает излучение только одного типа поляризации. Для нахождения вкладов излучения различной поляризации в областях энергии кванта, где существенно поглощение излучения обеих поляризаций, необходимо использовать второй метод.

На рис. 6 показаны спектры поглощения для двух поляризаций излучения при двух температурах решетки. В диапазоне энергий кванта 140-220 мэВ для получения спектров использовался первый метод, в диапазоне 70-140 мэВ - второй. Положение спектральных особенностей поглощения соответствует рассчитанным значениям. Широкий пик поглощения, обнаруженный вблизи энергии кванта 90 мэВ для ТЕ-поляризованного света, связан с оптическими переходами дырок из основного акцепторного состояния во вторую подзону $l h$ при $k_{\|} \neq 0$ (см. стрелки на рис. 1). В спектрах поглощения для обеих поляризаций был обнаружен узкий пик при энергии кванта $\sim 90$ мэВ, связываемый нами с оптическими переходами дырок из основного акцепторного состояния на дно второй дырочной подзоны $l h$. Его малая ширина и наличие для обеих поляризаций света могут быть связаны с сингулярностью приведенной плотности состояний. Пики поглощения при энергиях кванта $\sim 110$ и 130 мэВ связаны с переходами во вторую дырочную подзону при $k_{\|} \neq 0$ и также могут быть объяснены особенностями в плотности состояний [16]. Пик поглощения вблизи энергии кванта 150 мэВ, наблюдаемый для ТМ-поляризованного света, связан с переходами дырок из основного акцепторного состояния на дно третьей дырочной подзоны. Было обнаружено заметное красное смещение этого пика с ростом температуры, связанное с температурным сдвигом третьей подзоны квантовой ямы из-за изменения величины разрыва валентной зоны на гетерограницах слоев, формирующих КЯ. Подобное красное смещение с ростом температуры решетки было ранее нами обнаружено при расчетах [26] и экспериментально подтверждено [27] для межподзонных оптических переходов в гетероструктуре с двойными квантовыми ямами GaAs/AlGaAs. Пик поглощения, расположенный вблизи энергии кванта 205 мэВ для ТЕ-поляризованного света, связан с оптическими переходами дырок из основного акцепторного состояния в континуум делокализованных состояний над КЯ. Положение данного пика не могло быть точно определено в наших расчетах, так как в них учитывалось только возмущение от первых двух дырочных подзон. Отметим, что для ТМ-поляризованного света вероятность оптических переходов в сплошной спектр довольно мала [16], что подтверждается в наших экспериментах, в которых соответствующий пик был обнаружен только для излучения ТЕ-поляризации. Эксперименты показали, что интенсивность всех наблюдаемых пиков поглощения уменьшается с ростом температуры решетки. При температурах решетки, превышающих $160 \mathrm{~K}$, пики поглощения, связанные с примесями, перестают наблюдаться в спектрах. Это обусловлено термической ионизацией примесей при высоких температурах решетки. Оценки концентрации нейтральных акцепторов в КЯ показали, что при температуре $160 \mathrm{~K}$ $\sim 50 \%$ примесей ионизованы, тогда как при комнатной температуре ионизовано $>85 \%$ примесей. Оценки для низких температур согласуются с результатами эксперимента, поскольку мы не обнаружили какоголибо ярко выраженного пика, соответствующего межподзонным переходам из первой дырочной подзоны $h h$ в вышележащие состояния или в состояния континуума в наблюдаемом диапазоне энергий кванта. Только при температурах решетки $>160 \mathrm{~K}$ в спектре поглощения $s$-поляризованного света начинает проявляться слабое плечо, связываемое с межподзонными переходами дырок из первой $(h h)$ во вторую $(l h)$ дырочную подзону.

Таким образом, положения всех пиков на спектрах поглощения совпадают с положениями пиков фототока (см. рис. 5). Следует отметить, что при сравнении спектров поглощения и зонной диаграммы надо учитывать, что в спектр поглощения помимо закона дисперсии вносят вклад спектральные особенности оптического матричного элемента [16].

Исследования спектров примесного поглощения в квантовых ямах $p$-GaAs/AlGaAs показали, что коэффициент поглощения может достигать значений $\sim 10^{3} \mathrm{~cm}^{-1}$. Такие значения коэффициента поглощения делают эти структуры перспективными для создания 
длинноволновых инфракрасных фотоприемников и модуляторов. Отметим, что, как уже отмечалось, структуры с квантовыми ямами $p$-типа имеют преимущества по сравнению с квантовыми ямами, легированными донорами, поскольку в первом случае возможны оптические переходы для нормального падения света, т.е. для TЕ-поляризации. Результаты исследований примесных оптических переходов могут также использоваться в качестве физической основы для разработки приемников и модуляторов дальнего и среднего инфракрасного излучения в условиях электрической и оптической накачки.

\section{5. Заключение}

В работе исследованы спектры фотопроводимости структур с квантовыми ямами $p$-GaAs/AlGaAs при криогенных температурах в широком спектральном диапазоне. Положение особенностей в спектрах соответствуют сделанному ранее расчету энергетического спектра примесных уровней и подзон размерного квантования. В спектрах фотопроводимости обнаружен богатый набор особенностей, которые объясняются переходами дырок из основного состояния примеси на возбужденные и резонансные состояния примеси, а также в вышележащие дырочные подзоны. Измерены и проанализированы спектры примесного поглощения для разных поляризаций излучения при разных температурах $(4-300 \mathrm{~K})$. Обнаружены примесные пики поглощения и объяснена их природа. Основной вклад в поглощение вносят переходы дырок из основного состояния примеси в первую и вторую дырочные подзоны, а также процессы фотоионизации при переходах из основного примесного состояния в спектр делокализованных состояний, расположенный выше квантовой ямы. Получено хорошее соответствие между спектрами фотопроводимости, поглощения и теоретическим расчетом энергетического спектра состояний дырок и акцепторов в КЯ. Эксперименты подтвердили применимость метода конечных разностей для квантования гамильтониана Латтинжера. Большая величина полученного значения коэффициента поглощения делает структуры с квантовыми ямами GaAs/AlGaAs, легированными акцепторами, перспективными для создания длинноволновых инфракрасных фотоприемников и модуляторов.

\section{Благодарности}

Авторы выражают благодарность А.Н. Софронову за помощь в расчетах.

\section{Финансирование работы}

Исследование выполнено при финансовой поддержке Министерства образования и науки РФ (государственное задание) и гранта РНФ 18-72-00034.

\section{Конфликт интересов}

Авторы заявляют, что у них нет конфликта интересов.

\section{Список литературы}

[1] R.M. Woodward, B.E. Cole, V.P. Wallace, R.J. Pye, D.D. Arnone, E.H. Linfield, M. Pepper. Phys. Med. Biol., 47, 3853 (2002).

[2] M.C. Kemp, P.F. Taday, B.E. Cole, J.A. Cluff, A.J. Fitzgerald, W.R. Tribe. Terahertz Milit. Sec. Appl., 5070, 44 (2003).

[3] A.J. Fitzgerald, B.E. Cole, P.F. Taday. J. Pharm. Sci., 94 (1), 177 (2005).

[4] А.С. Скрыль, М.В. Царев. Применение терагерцового излучения для исследования предметов искусства (Нижегородский ун-т, Нижний Новгород, 2011).

[5] H.W. Hubers, S.G. Pavlov, H. Riemann, N.V. Abrosimov, R.Kh. Zhukavin, V.N. Shastin. Appl. Phys. Lett., 84 (18), 3600 (2004).

[6] S.G. Pavlov, N. Deßmann, V.N. Shastin, R.Kh. Zhukavin, B. Redlich, A.F.G. van der Meer, M. Mittendorff, S. Winnerl, N.V. Abrosimov, H. Riemann, H.-W. Hubers. Phys. Rev. X, 4, 021009 (2014).

[7] А.В. Андрианов, А.О. Захарьин, Ю.Л. Иванов, М.С. Кипа. Письма ЖЭТФ, 91 (2), 102 (2010).

[8] А.В. Андрианов, А.О. Захарьин, И.Н. Яссиевич, Н.Н. Зиновьев. Письма ЖЭТФ, 79 (8), 448 (2004).

[9] W.T. Masselink, Y.-C. Chang, H. Morkoc. Solid State Electron., 29 (2), 205 (1986).

[10] A. Blom, M.A. Odnoblyudov, I.N. Yassievich, K.A. Chao. Phys. Rev. B, 68, 165338 (2003).

[11] D. Stehr, C. Metzner, M. Helm, T. Roch, G. Strasser. Phys. Rev. Lett., 95, 257401 (2005).

[12] Д.А. Фирсов, Л.Е. Воробьев, В.Ю. Паневин, А.Н. Софронов, Р.М. Балагула, И.С. Махов, Д.В. Козлов, А.П. Васильев. ФТП, 49 (1), 30 (2015).

[13] I.S. Makhov, V.Yu. Panevin, D.A. Firsov, L.E. Vorobjev, A.P. Vasil'ev, N.A. Maleev. J. Luminesc., 210, 352 (2019).

[14] I.S. Makhov, V.Yu Panevin, D.A. Firsov, L.E. Vorobjev, G.V. Klimko. J. Appl. Phys., 126 (17), 175702 (2019).

[15] N.W.M. Zheng, M.P. Halsall, P. Harmer. J. Appl. Phys., 92, 6039 (2002).

[16] H.H. Chen, Y.-H. Wang, M.-P. Houng. IEEE J. Quant. Electron., 32 (3), 471 (1996).

[17] M.Ya. Vinnichenko, I.S. Makhov, V.Yu. Panevin, L.E. Vorobjev, S.V. Sorokin, I.V. Sedova, D.A. Firsov. Phys. E: Low-Dim. Systems and Nanostructur., 124, 114301 (2020).

[18] J.S. Blakemore. Semiconductor statistics (Mineola, N.Y., 2002).

[19] W.T. Masselink, Y.C. Chang, H. Morkoc. Phys. Rev. B, 32 (8), 5190 (1985).

[20] G.T. Einevoll, Y.C. Chang. Phys. Rev. B, 41 (3), 1447 (1990).

[21] P.A. Belov. Phys. E: Low-Dim. Systems and Nanostructur., 112, 96 (2019).

[22] A.T. Hunter, T.C. McGill. Appl. Phys. Lett., 40 (2), 169 (1982).

[23] R. Dingle, C. Weisbuch, H.L. Stormer, H. Morkoc, A.Y. Cho, Appl. Phys. Lett., 40 (6), 507 (1982).

[24] K.R. Elliott. Appl. Phys. Lett., 42 (3), 274 (1983).

[25] J.C. Borgoin, H.J. von Bardeleben, D. Stievenard. J. Appl. Phys., 64 (9), (1988).

[26] V. Akimov, D.A. Firsov, C.A. Duque, V. Tulupenko, R.M. Balagula, M.Y. Vinnichenko, L.E. Vorobjev. Optical Mater., 66, 160 (2017). 
[27] Д.А. Фирсов, Л.Е. Воробьев, М.Я. Винниченко, Р.М. Балагула, М.М. Кулагина, А.П. Васильев. ФТП, 49 (11), 1473 (2015).

Редактор Г.А. Оганесян

\section{Infrared light absorption and photoconductivity in $p$-GaAs/AIGaAs quantum wells}

M.Ya. Vinnichenko ${ }^{1}$, I.S. Makhov' ${ }^{1}$, N.Yu. Kharin ${ }^{1}$, S.V. Graf ${ }^{1}$, V.Yu. Panevin ${ }^{1}$, I.V. Sedova ${ }^{2}$, S.V. Sorokin ${ }^{2}$, D.A. Firsov ${ }^{1}$

${ }^{1}$ Peter the Great St. Petersburg Polytechnic University, 195251 St. Petersburg, Russia

${ }^{2}$ loffe Institute,

194021 St. Petersburg, Russia

Abstract The spectra of low-temperature impurity-assisted far and mid-infrared photoconductivity and absorption in nanostructure with multiple GaAs/AlGaAs quantum wells doped with acceptors are investigated. The experimentally obtained absorption and photoconductivity spectra correlate well with each other. According to the hole and acceptor state energy spectrum calculations the spectral features related to the optical hole transitions from the ground acceptor state to the delocalized states of valence subbands, to the excited acceptor states and to the delocalized states above the quantum well (photoionization) are identified in the absorption and photoconductivity spectra. 